Materials Science and Engineering A: Structural Materials: Properties, Microstructures and Processing, Volume 747, 18 February 2019, pp. 111-118

DOI:10.1016/j.msea.2018.12.114

\title{
Improving mechanical properties of wire plus arc additively manufactured maraging steel through plastic deformation enhanced aging response
}

Xiangfang Xu*, Supriyo Ganguly, Jialuo Ding, Philip Dirisu, Filomeno Martina, Xianwei Liu, Stewart W. Williams

Welding Engineering and Laser Processing Centre, Cranfield University, Bedford, MK43 0AL, UK

\begin{abstract}
Maraging steel gains ultrahigh strength through aging; however, wire plus arc additively manufactured maraging steel features a columnar-dendritic structure with associated segregation and shows a much less pronounced aging response. In this paper, plastic deformation was introduced through interpass cold rolling during the layer-by-layer deposition process. After aging, the ultimate tensile strength (UTS) was improved substantially from $1410 \mathrm{MPa}$ (unrolled) to $1750 \mathrm{MPa}(50 \mathrm{kN}$ rolled). Rolling induced partial recrystallization to break the dendritic structure and form high-angle grain boundaries, which promoted the atoms diffusion to enable a more uniform solutionizing process and improved the subsequent aging response by $105-110 \%$. The main contribution of overall strengthening of the rolled alloy was attributed to the effective aging process, accounting for more than $95 \%$ of the entire strength increase.
\end{abstract}

Keywords: wire plus arc additive manufacture; plastic deformation; maraging steel; dislocation density; age hardening

\footnotetext{
* Corresponding author.

E-mail address: xiangfang.xu@cranfield.ac.uk (X. Xu).
} 


\section{Introduction}

Maraging steel is a family of low-carbon (below $0.03 \%$ ) steel that combines ultrahigh strength with excellent fracture toughness [1]. Maraging steel derives the high strength by the dispersion of large amount of nanosized precipitates from the age hardening of an extremely ductile bodycentred cubic (bcc) lath martensitic structure. The unique hardening mechanism results in strengths up to $3450 \mathrm{MPa}$ [2], as compared to other steels with similar crystallographic structures. The high strength-to-weight ratio, ease of machining in the annealed condition, superior dimension stability during age hardening, and good weldability make maraging steel widely used in aerospace and tooling industry.

Additive Manufacture (AM) is a novel approach for building near-net-shape components in a layer-by-layer manner [3]. In Directed Energy Deposition (DED) AM, the feedstock (powder or wire) is melted by a heat source (laser, electron beam or arc), and the deposition path is controlled by a robot or a CNC system to form the desired geometry. Compared to conventional subtractive manufacture (SM), AM is attractive for the fabrication of metallic components due to substantially reduced material wastage of expensive metals (such as Ti-6Al-4V, Inconel superalloys and maraging steels), shortened lead times and greater design freedom [4].

Despite these advantages, the implementation of AM in engineering applications requires the AM parts to possess equivalent or even superior mechanical properties to the SM counterparts. Currently, the benefits above are not realised due to the limitation in properties, and AM is mostly exploited in powder bed processes where the design capability is utilised to provide weight savings. The conventional metal billet or forging production procedure involves melting, casting and subsequent thermomechanical processing, through which the entire billet or forging undergoes a uniform processing and ends up with a relatively homogeneous microstructure and largely isotropic characteristics [5]. Due to the inherent characteristics of DED AM, the deposited material undergoes a unique processing featuring localised melting, 
rapid solidification and non-uniform heating-cooling cycles. These conditions often result in a spatially differential microstructure of dendritic nature associated with segregation and largely anisotropic properties in comparison to that attained in a conventionally processed material [6]. For example, in $\mathrm{AM}$ of Ti-6Al-4V alloy, undesirable, coarse-columnar, primary $\beta$ grain structures have been widely reported to result in a strong texture and mechanical anisotropy in an AM component in contrast to the fine equiaxed grains, nearly random grain orientation and isotropic mechanical properties in a wrought alloy $[7,8]$.

Most of the AM research on maraging steels focussed on the laser/powder based process [1,914]; however, the solidification could results in non-steady amorphous-nanocrystalline composite microstructures [14] due to the extremely high cooling rate (up to $10^{8} \mathrm{~K} / \mathrm{s}$ [15]). Furthermore, unmelted particles or lack of fusion defects (micrometre scale) often result in components that are not fully-dense (relative density ranging from $90.9 \%$ to $99.9 \%$ [11]). In an earlier study the authors used Wire plus Arc Additive Manufacture (WAAM) [4], a DED AM process using wire as the feedstock and an arc as the heat source, to deposit fully-dense maraging steel components $[6,16]$. The resulting microstructure featured severe elemental segregations and a large proportion of columnar grains. The tensile strength of the WAAM maraging steel was comparable to the wrought alloy in the as-deposited condition (1118MPa vs $1000 \mathrm{MPa}$ [6]), but much lower in the aged condition (1410MPa [6] vs $1760 \mathrm{MPa})$, which was mainly attributed to the lower aging response of the WAAM microstructure.

AM process is similar to casting since both involve melting and solidification process. The AM components are built through the solidification of liquid metal droplets and therefore are likely to exhibit the disadvantages associated with solidified structures, e.g. dendritic structure and segregation. Wrought alloys obtain superior properties to cast alloys due to the additional thermomechanical processing to eliminate the elemental segregation and induce recrystallization. For instance, by applying cold rolling to maraging steels, the remaining 
austenite in the as-quenched samples was transformed to martensite and the plastic deformation induced high-density dislocations accelerated the hardening response during the subsequent aging process; when applying $15 \%$ thickness reduction, the yield strength was reported to improve from 1286MPa to $1700 \mathrm{MPa}[17]$.

In order to achieve comparable microstructural features and mechanical properties to the wrought alloys, rolling had been applied to different WAAM alloys. For Ti-6Al-4V, it was found that the coarse centimetre-scale columnar $\beta$ structure was refined to below $100 \mu \mathrm{m}$ and both $\alpha$ and $\beta$ phase textures were weakened to close to random [7]. For aluminium alloy, rolling proved to eliminate pores larger than $5 \mu \mathrm{m}$ in diameter [18] and enhanced the microhardness and tensile strength due to the high-density dislocations and fine sub-grains [19]. For low alloy steel, rolling with profiled and slotted roller was reported to reduce the distortion, surface waviness and residual stress; grain refinement was also observed when the rolled alloy was reheated during subsequent depositions [20].

With the aim to improve the mechanical properties of WAAM maraging steel to the level comparable to the wrought alloy, the present research studied the application of interpass cold rolling to induce plastic deformation during the layer-by-layer deposition process. Although cold rolling with different thickness reduction ratios has been shown to enhance the aging response of wrought maraging steel, interpass rolling in WAAM process, where rolling and deposition are applied alternatively, is a totally different scenario. Rolling-induced plastic strain would be partially released by the following depositions, and the non-equilibrium intrinsic aging effect [14] also makes the rolled microstructure, phase distribution and mechanical properties unpredictable. Therefore, the efficacy of using interpass cold rolling, the final microstructure, and the aging response of the rolled WAAM maraging steel are yet to be investigated, and so is the underlying strengthening mechanism, which are the subject of the present paper. 


\section{Experimental procedures and characterization}

2.1 Interpass rolling assisted WAAM process

The experimental setup consisted of a deposition system and a rolling system, as shown in Fig.

1. The former consisted of a plasma power source (Fronius, TransTig 5000) and a wire feeder;

a trailing shield device [21] was attached around the torch to provide additional shielding (99.99\% Ar, $2001 / \mathrm{min})$ and prevent the deposits from being excessively oxidised after deposition. A three-axis CNC gantry system was deployed to control the deposition paths, and the same rolling assembly (as reported in $[7,8,19,20,22]$ ) was attached to the CNC gantry. A rigid flat roller (width: $20 \mathrm{~mm}$, diameter: $100 \mathrm{~mm}$ ) was placed above and aligned with the deposition paths; after each deposition, the roller was lowered down to apply compressive pressure to the deposit through a hydraulic cylinder. As the rolling rig travelled along (speed: $2 \mathrm{~m} / \mathrm{min}$ ), the deposit was flattened through the plastic flow of the material, thereby introducing strain and stored energy to the deposit. In this study, the interpass rolling strategy was adopted, i.e., rolling and deposition were applied in an alternating manner.

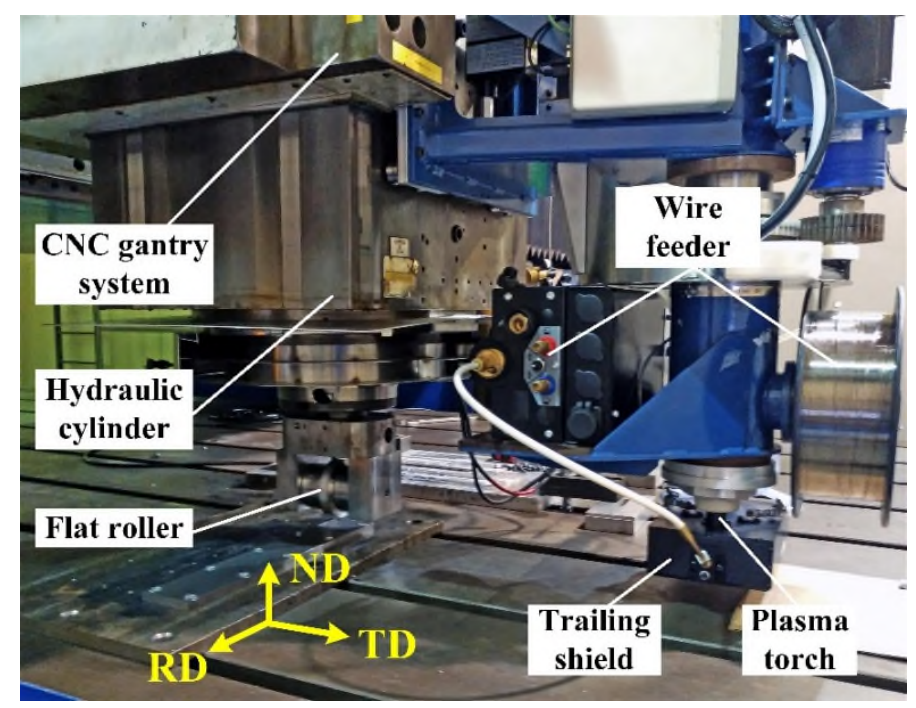

Fig. 1. Experimental setup of the interpass rolling assisted WAAM system. (RD: rolling direction; ND: normal direction; TD: transverse direction.) 
Two interpass rolled linear wall structures of the same length $(400 \mathrm{~mm})$ and height $(123 \mathrm{~mm})$ were produced along the $\mathrm{RD}$ with the load of $50 \mathrm{kN}$ and $75 \mathrm{kN}$ respectively for mechanical testing and microstructural analysis. Rolling was applied when the topmost deposit cooled down below $121^{\circ} \mathrm{C}$, as suggested by [23], to minimise the austenite formation. To ensure consistency with the previous research [6] and therefore a meaningful comparison of the mechanical test results, the same wire (see Table 1), deposition parameters (current 180A, wire feed speed $1.8 \mathrm{~m} / \mathrm{min}$, travel speed $0.2 \mathrm{~m} / \mathrm{min}$ ) and heat treating procedure (solutionizing at $815^{\circ} \mathrm{C}$, air cooling to room temperature; then aging at $482^{\circ} \mathrm{C}$ for $3 \mathrm{~h}$ and air cooling to room temperature) were applied to this study.

Table 1. The chemical composition of the maraging steel wire (wt. \%).

\begin{tabular}{lllllll}
\hline Ni & Mo & Co & Ti & Al & C & Fe \\
\hline 18.28 & 4.69 & 8.21 & 0.44 & 0.11 & $<0.01$ & Balance \\
\hline
\end{tabular}

\subsection{Analytical methods}

The samples were extracted from the WAAM part along the ND-TD plane, then mounted, ground and polished for the metallographic analysis. Samples were etched with $10 \%$ Nital solution for $10 \mathrm{~s}$ for microstructure observation, and for $60 \mathrm{~s}$ to reveal the prior-austenite grain boundaries. The electron backscattered diffraction (EBSD) was carried out to characterize the grains and the texture. Tensile test was carried out with using the 5500R electromechanical testing machine (load cell: $100 \mathrm{kN}$, crosshead speed: $1 \mathrm{~mm} / \mathrm{min}$ ), and the tensile specimens were extracted in both horizontal (along wall length) and vertical direction (along wall height) according to BS EN ISO 6892-1: 2009 standard [6]. At least three specimens were tested for each direction and heat treating condition, and t-test [24] was applied to check the statistically difference of the testing results (statistical significance threshold $=0.05$ ). The grain size is determined using the line intercept method [25]. Austenite quantification by X-ray diffraction 
(XRD; SIEMENS D5005, $\mathrm{Cu} \mathrm{K} \alpha$ radiation, $\lambda=1.5418 \AA$ ) was carried out using the direct comparison method [6]. Transmission electron microscopy (TEM; JEM-2100F, JEOL) operating at $200 \mathrm{kV}$ was used to characterise the dislocation distribution. The thin-foil TEM samples were prepared by focused ion beam (FIB).

\section{Results}

\subsection{Microhardness}

Fig. 2 presents the microhardness variation of the unrolled and interpass rolled WAAM maraging steel wall structures. In the as-deposited condition (Fig. 2a), the microhardness of all the samples shows a low level of 30-35HRC near the top and then a sudden rise to 40-45HRC towards the substrate. The only difference is where the rise begins, and it turns out that the rolled alloys possess a larger softer zone. As has been explained in [6], the material near the top is softer due to the lack of subsequent thermal cycles so that no appreciable intrinsic aging [14] occurs to harden the matrix. The critical point where pronounced aging firstly takes place is where the microhardness rises sharply; in terms of metallographic morphology, it is where the topmost layer band [6] locates (see dash lines in Fig. 2). After aging (Fig. 2b), the microhardness of all the samples is greatly improved to the same high level of 50-53HRC. The microhardness variation from the top to the bottom is also eliminated.

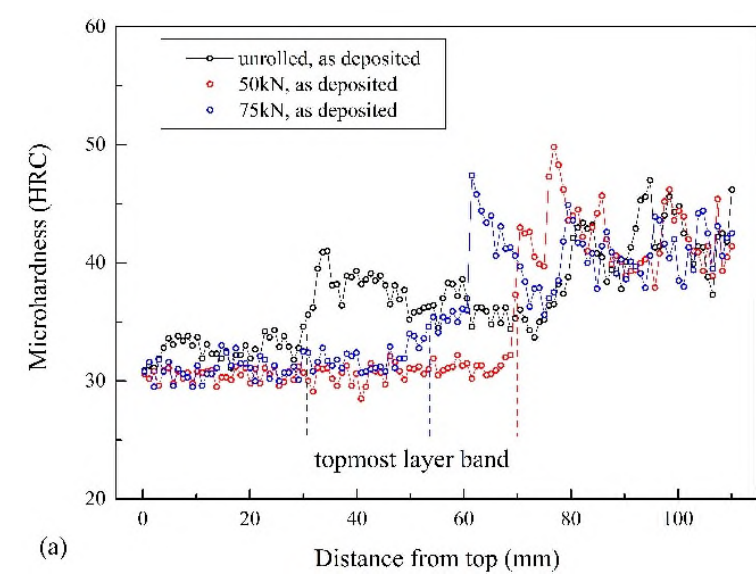

(a) as deposited condition

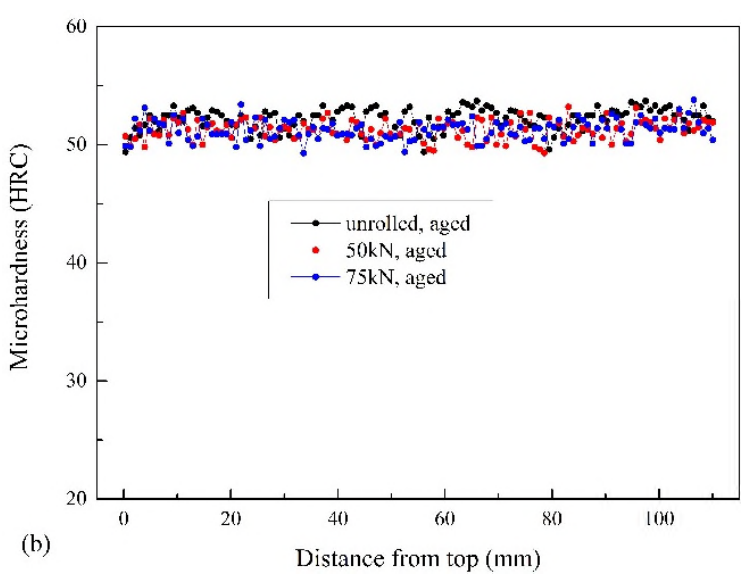

(b) aged condition 
Fig. 2. Microhardness variation of WAAM maraging steel wall from the top to the substrate.

\subsection{Dendrites reorientation}

Fig. 3 presents the optical micrographs of the $75 \mathrm{kN}$ rolled WAAM maraging steel in the aged condition. In the topmost layer (Fig. 3a), where rolling and the subsequent thermal cycles are absent, the microstructure shows a typical cellular/dendritic solidification morphology. Bundles of long and linear columnar dendrites are observed to develop across the layers and perpendicular to the interlayer boundaries. The austenite shown as white pools is found dispersed in the martensitic matrix preferentially at the interdendritic area (Fig. 3a). At 20mm away from the top (Fig. 3b), the layer shows as being squeezed. The linear columnar dendrites are replaced by many short and highly-distorted sub-columnar dendrites with random orientation; the size of the columnar dendrites is thereby greatly reduced, and the long dendrites tend to evolve to a more cellular structure through recrystallization. At some point, the dendritic structure can fully evolve into a cellular one (Fig. 3c), and the deformed cells are more preferentially oriented along TD. In addition, austenites are found to disperse among the intercellular regions with the aspect ratio greatly reduced.
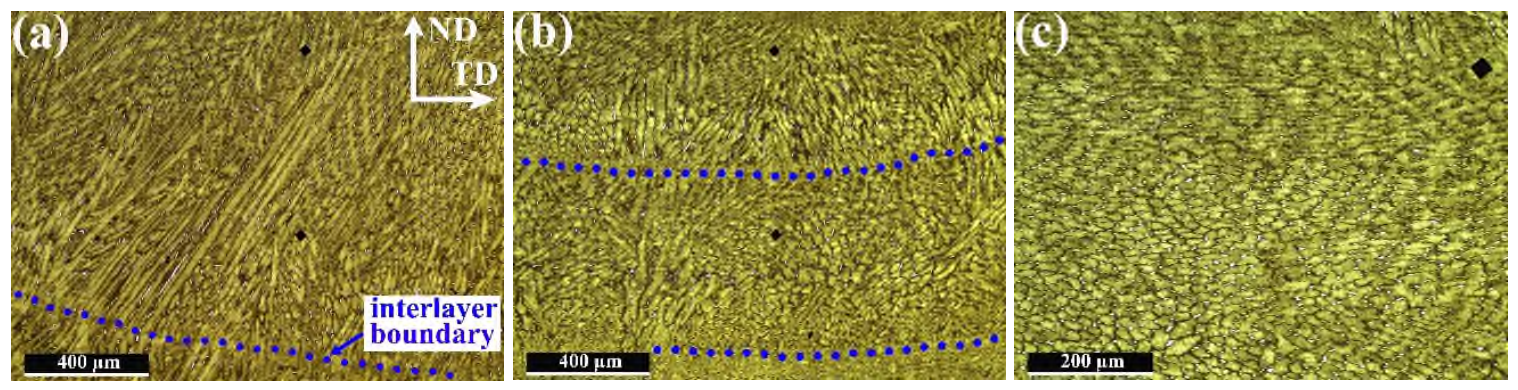

Fig. 3. Optical micrographs of the $75 \mathrm{kN}$ rolled WAAM maraging steel at (a) topmost layer (b) $20 \mathrm{~mm}$ and (c) $40 \mathrm{~mm}$ down away from the top. Please note the black marks are hardness test indentations, not porosities. 


\subsection{Grain recrystallization}

Fig. 4 shows the grain micrographs of the WAAM maraging steel in the as-deposited condition. Images are all taken at $25 \mathrm{~mm}$ away from the top surface (right above the topmost layer band of the unrolled alloy). Some exemplary prior-austenite grain boundaries are marked with black lines for better visibility. Long and columnar grains are observed to grow along ND in the unrolled alloy; after rolling, those low-angle grains evolve to a large number of high-angle grains through recrystallization induced by the rolling and subsequent heat-cooling process. Segregation sites are not observed at the same position in the rolled micrographs, indicating a more homogeneous structure after rolling.
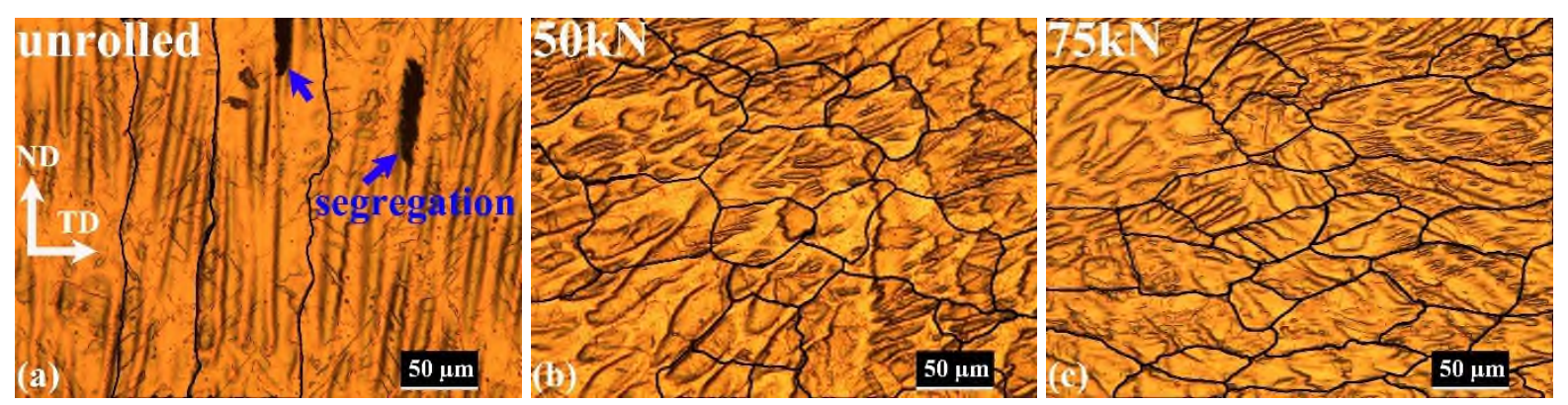

Fig. 4. Optical micrographs showing the prior-austenite grain boundaries of the (a) unrolled (b) $50 \mathrm{kN}$ and (c) $75 \mathrm{kN}$ rolled WAAM maraging steel.

\subsection{Mechanical testing results}

Fig. 5 presents the mechanical testing results of the WAAM maraging steel attained after interpass rolling (see Table 2 in the appendix for detailed data). The UTS and $0.2 \%$ YS tested in the horizontal direction show a more pronounced standard deviation due to the intrinsic aging effect causing different levels of hardening along the wall height. In the as deposited condition, $50 \mathrm{kN}$ rolling results in a slight UTS change of $20 \mathrm{MPa}(\mathrm{t}$-test, $\mathrm{p}$-value $=0.83$ ) and $13 \mathrm{MPa}$ (t-test, $\mathrm{p}$-value $=0.33$ ) in the horizontal and vertical direction respectively, whilst $75 \mathrm{kN}$ results in a $34 \mathrm{MPa}$ (t-test, $\mathrm{p}$-value $=0.66$ ) and $4 \mathrm{MPa}$ change respectively; therefore rolling does not have any statistically-significant effect on the strength. After aging, the UTS obtained with 
$50 \mathrm{kN}$ rolling is significantly improved from $1138 \mathrm{MPa}$ to $1750 \mathrm{MPa}$, and from $1013 \mathrm{MPa}$ to $1735 \mathrm{MPa}$ in the horizontal and vertical directions respectively, which is very close to the wrought alloy (1760MPa). Rolling with a higher load of $75 \mathrm{kN}$ does not show further strength improvement in the horizontal direction after aging. The elongation generally reduces after aging, and the WAAM alloy shows inferior elongation to the wrought alloy in the aged condition; therefore, rolling does not improve the ductility. Even though the $0.2 \% \mathrm{YS}$ and elongation of the rolled material are slightly inferior to the wrought alloy, the overall WAAM maraging steel is hardened to a considerable level to marginally reach the wrought level through the applied interpass rolling.

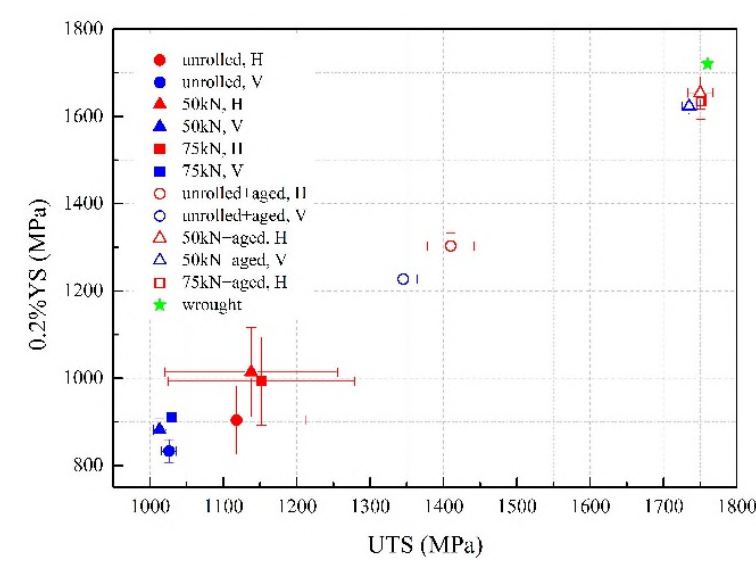

(a) UTS- $0.2 \%$ YS

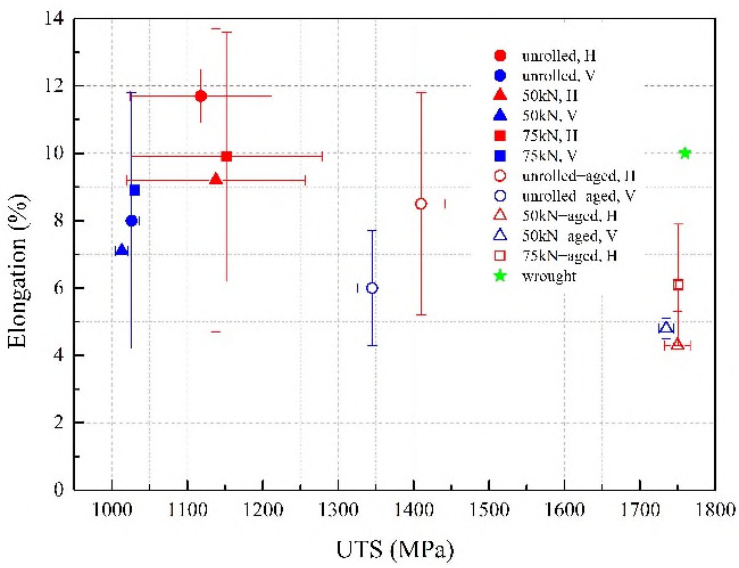

(b) UTS-Elongation

Fig. 5. Mechanical properties of the WAAM maraging steel (H-horizontal, V-vertical; error bar represents the standard deviation).

\section{Discussion}

4.1 Effects of rolling on the deposit

\subsubsection{Dislocation multiplication}

Plastic deformation of the top deposit results in the increase of dislocation density within the crystal structure through the elongation of existing dislocations and generation of massive new 
dislocations through the Frank-Read mechanism [26]. Fig. 6 compares the dislocation quantity of the unrolled and $75 \mathrm{kN}$ rolled WAAM maraging steel. In the unrolled alloy (Fig. 6a), dislocations formed during the solidification process are found to tangle with each other within the martensitic laths. After rolling (Fig. 6b), the overall dislocation density is significantly increased with the newly generated dislocations added up; higher-density dislocation clusters are observed in the laths and generally do not uniformly arrange themselves in the rolled alloy.
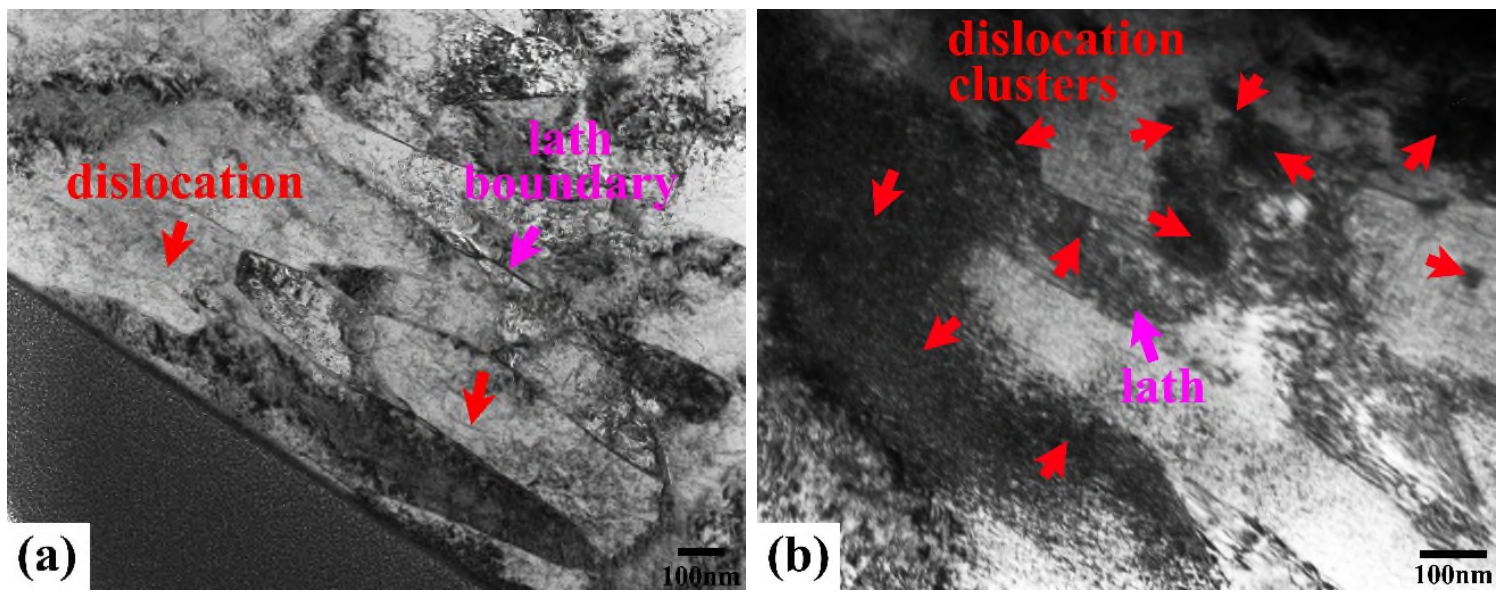

Fig. 6. TEM bright field images showing dislocations in the (a) unrolled and (b) $75 \mathrm{kN}$ rolled WAAM maraging steel in the as deposited condition.

\subsubsection{Energy stored in the deposit}

Upon rolling, the deposit is flattened by squeezing the material so that the deposit gets shorter in the ND and wider in the TD. Consequently, the rolling system works on the deposit by transferring the mechanical energy to the internal energy. The internal energy is stored in the deposit and results in the crystal defects such as stacking faults, point defects, dislocations, and twins which provide the driving force for a series of metallurgical reactions to take place [8] during the complex rolling assisted WAAM process, as will be described later on.

\subsubsection{Texture weakening}

Fig. 7 presents the pole figures of the martensitic matrix of the unrolled and rolled WAAM maraging steel measured at the same area as Fig. 4. A strong texture in $\{100\}$ family planes is 
observed in the unrolled condition, with the main axis having an intensity of 15 times random; after rolling, the intensity is reduced to 2.57 and 3.55 times random with $50 \mathrm{kN}$ and $75 \mathrm{kN}$ rolling respectively. Due to the directional thermal conduction (from top to bottom) in the WAAM solidification process, some facets of a crystal grow faster ( $\{100\}$ in cubic structures) than others and the crystals at which one of these planes faces in the direction of growth will usually out-compete crystals in other orientations. Furthermore, the cyclic heating from subsequent layers and the inherent low thermal conductivity of maraging steel $(19.7 \mathrm{~W} / \mathrm{mK}$, about $1 / 3$ of $0.5 \% \mathrm{C}$ steel) allow enough activation energy and time for atoms to find places in existing crystals, rather than starting new crystals with a random orientation. Consequently, directional growth of columnar grains is observed in the unrolled WAAM maraging steel. Interpass rolling causes a significant amount of flattening of the deposits, which destroys the crystalline order and reorients the crystallites in these directions by grain flow. In case of a subsequent thermal process, the new crystallites that arise will have a more random texture to weaken the overall texture that formed in the unrolled condition.
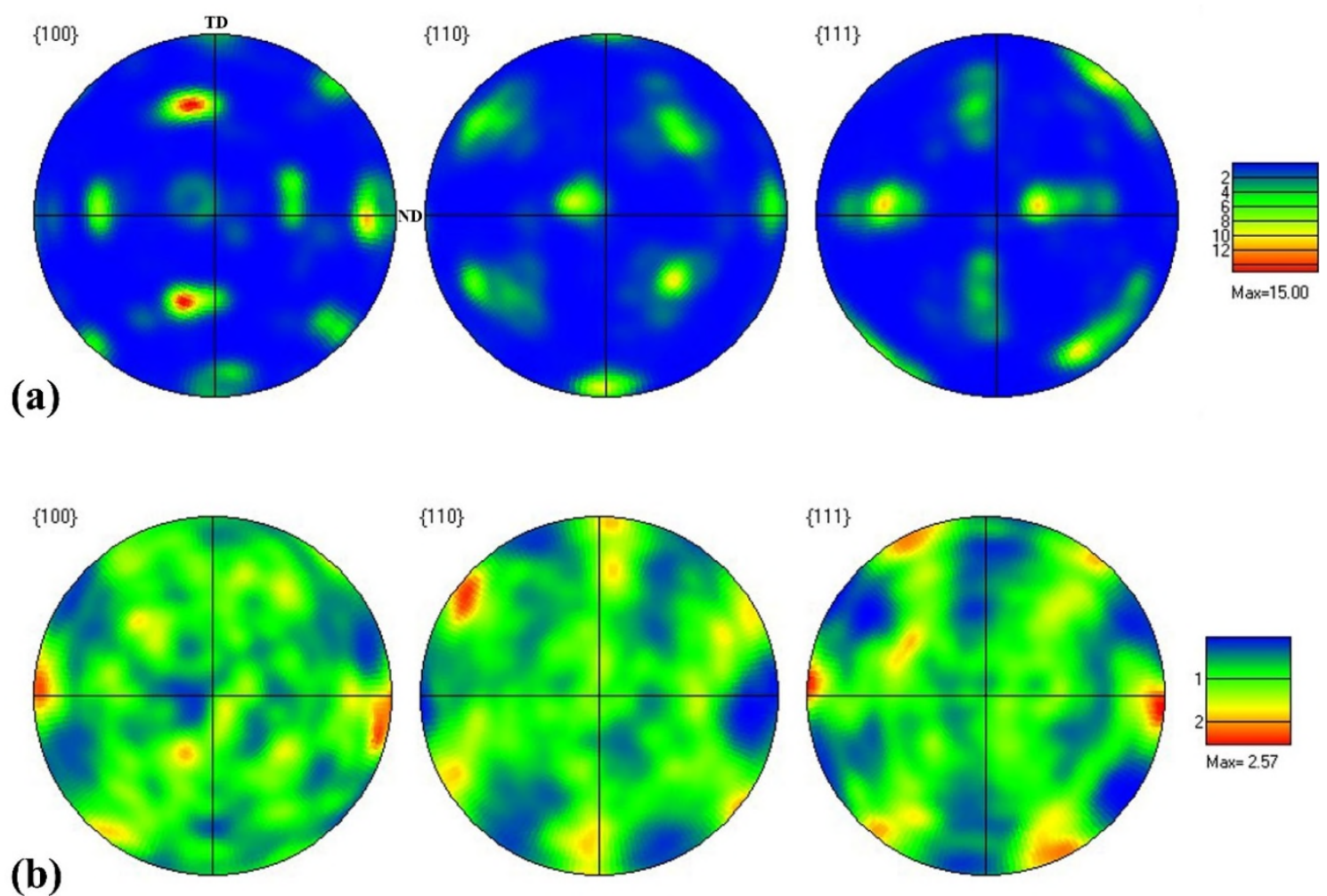

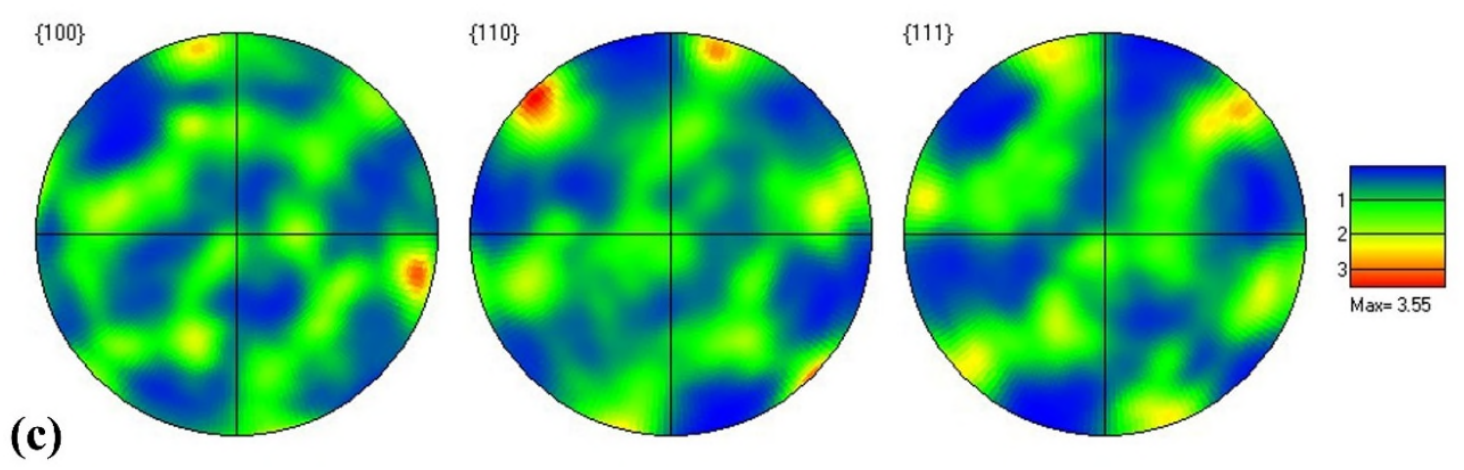

Fig. 7. Pole figures showing (a) strong $\{100\}$ texture in the unrolled condition and greatly weakened texture after rolling with (b) $50 \mathrm{kN}$ and (c) $75 \mathrm{kN}$ (half width: $10^{\circ}$, cluster size: $5^{\circ}$ ).

\subsection{Strengthening mechanisms}

\subsubsection{Grain boundary strengthening}

\subsubsection{Recrystallization}

It is worth noting that the recrystallization occurred during the rolling-WAAM process is different from a conventional one in three aspects. Firstly, the plastic deformation of the deposits is not in a one-shot thickness reduction manner but a non-uniform accumulative manner; secondly, the thermal history is in a fast-heating-fast-cooling manner featuring cyclic temperature pulses rather than a controlled process; thirdly, the recrystallization process is accompanied by the recovery process which releases the stored energy and reduces the activity of subsequent recrystallization process.

\subsubsection{Grain size}

Fig. 8 shows the EBSD grain reconstruction results in the same area as Fig. 4. In the unrolled alloy, the prior-austenite shows as columnar grains containing numerous subgrains and primarily orients along the building direction; the lengths are comparable to the entire map, and the thicknesses are generally less than $50 \mu \mathrm{m}$ (Fig. 8a). With $50 \mathrm{kN}$ rolling, the prioraustenite shows as equiaxed grains also containing a significant number of subgrains; the average grain size is $40 \mu \mathrm{m}$ which is comparable to the wrought alloy $(30 \mu \mathrm{m}$ [6]). Though rolling 
induced recrystallization have changed the grain morphology, the grain sizes are almost the same; hence the strengthening from grain size reduction will not be expected to be considerable.
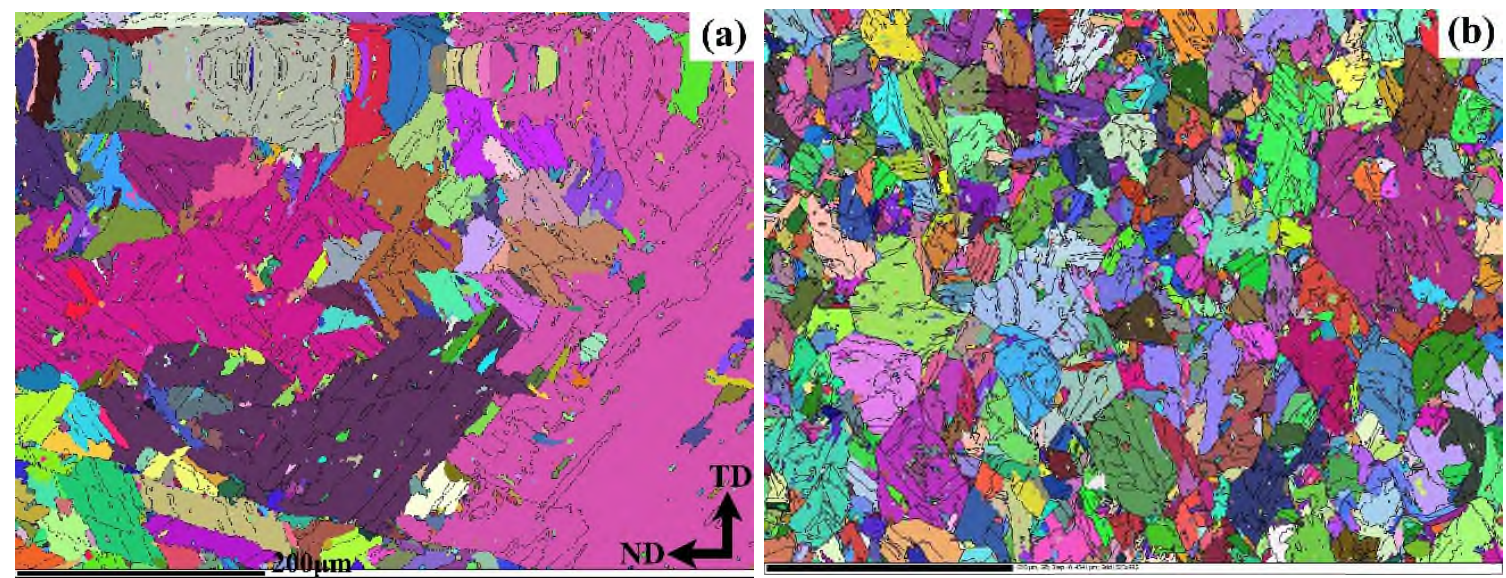

Fig. 8. Randomly coloured grains after grain reconstruction for (a) unrolled (b) $50 \mathrm{kN}$ rolled WAAM maraging steel (black lines are grain boundaries with misorientation greater than $15^{\circ}$ ).

\subsubsection{Precipitation hardening}

\subsubsection{Enhanced solutionizing process}

From Fig. 2, it is worth noting that after rolling the location of the topmost layer band is moved further away from the top, indicating an enlarged supersaturated martensitic area (the softer zone). The unrolled alloy shows an earlier and more pronounced response to the nonequilibrium intrinsic aging effect than the rolled one: the same amount of temperature pulses cannot provide enough driving force to trigger appreciable precipitation in the rolled alloy at the same location. It can thus be postulated that rolling promotes the alloying atoms diffusion and dissolution into the matrix to create a more supersaturated matrix, and the solute atoms tend to be more thermodynamically stable in the highly strained matrix. Besides, the high-angle grain boundaries formed as a result of recrystallization allow more atoms mobility and diffusion paths into solution. It is also postulated that the strong $\{100\}$ texture in the unrolled alloy does not favour the atoms dissolution from some crystal planes, as compared to the 
randomly oriented crystals. The more supersaturated matrix will then result in a more significant nucleation during solutionizing; in the subsequent aging stage, those nuclei will grow to form larger amount of precipitates to strengthen the matrix.

\subsubsection{Precipitates quantity}

When a moving dislocation meets the precipitates, the interaction ends up with the dislocation bypassing the precipitates in the form of Orowan looping or bypass slip if the precipitates are hard, or the precipitates being sheared if they are soft, thereby strengthening the material. Fig. 9 shows the precipitates and dislocations interacting within a lath of the aged WAAM maraging steel. Dispersed nanoscale precipitates embedded in the martensitic matrix are found as pinning points impeding the movement of the linear dislocations.

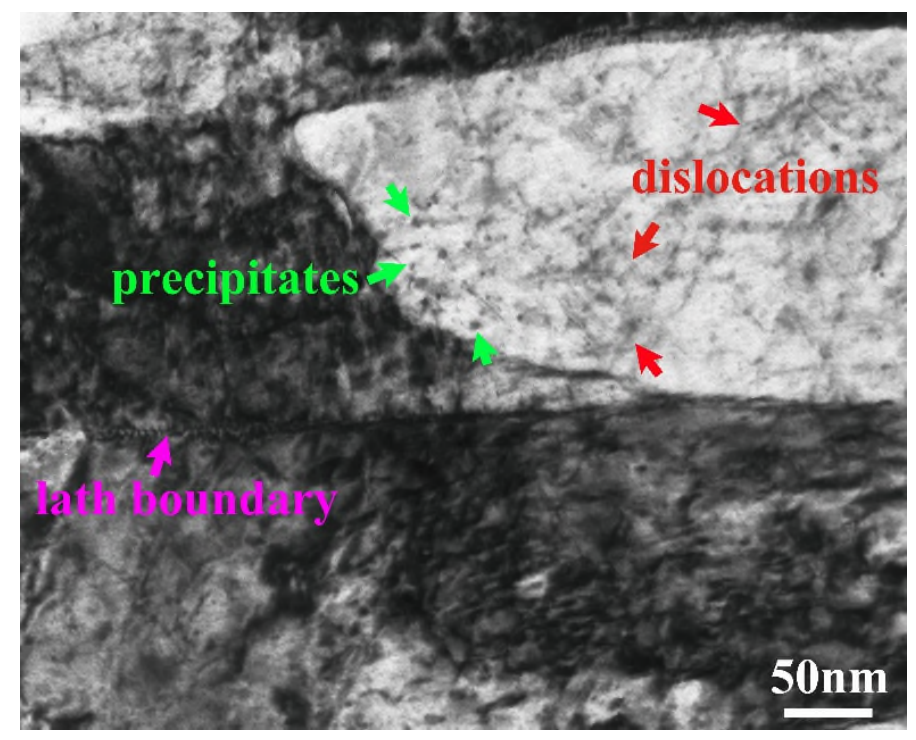

Fig. 9. TEM bright field image showing the precipitates impeding dislocation motion in the aged WAAM maraging steel.

The strengthening obtained from aging $\Delta \sigma_{a}$ is dependent on the metallic system, volume fraction and size of the precipitates [27]. Since the unrolled and rolled WAAM maraging steel possess the same alloying system and undergo identical heat treatment, the major difference 
between them is the volume fraction of precipitates after aging. By applying the Taylor factor to the Ashby-Orowan relationship [27], the $\Delta \sigma_{a}$ can be given by Equation (1)

$$
\Delta \sigma_{a}=\left(0.538 G b f^{1 / 2} / X\right) \ln (X / 2 b)
$$

Where $G$ is the shear modulus, $b$ is the Burgers vector of the dislocation, $f$ is the volume fraction of the precipitates and $X$ is the spatial diameter of the precipitate.

Table 3 compares the volumetric fraction of the precipitates formed in the aged WAAM alloy. The precipitates of interest are the most widely reported $\mathrm{Ni}_{3} \mathrm{Mo}, \mathrm{Ni}_{3} \mathrm{Ti}, \mathrm{Fe}_{2} \mathrm{Mo}$ and $\mathrm{Fe}_{7} \mathrm{Mo}_{6}[6]$. As can be seen, the quantity of precipitates formed are almost doubled after rolling, and there is no significant difference between $50 \mathrm{kN}$ and $75 \mathrm{kN}$ rolling. Therefore, the improved aging response of the rolled alloy can be attributed to two reasons: firstly, the high-density dislocations within the laths provide massively more preferred nucleation sites for the precipitates; secondly, the dislocations also increase the diffusion rate of solute atoms by providing preferred diffusion paths [28]. A larger amount of precipitates distort the lattice around them and together with the increased grain boundaries, act as barriers to the dislocation motion to provide extra strength to the WAAM maraging steel.

Table 3. The volume fraction of the precipitates measured through EBSD phase mapping (\%).

\begin{tabular}{lll}
\hline unrolled & $50 \mathrm{kN}$ rolled & $75 \mathrm{kN}$ rolled \\
\hline $1.4[6]$ & 2.2 & 2.4 \\
\hline
\end{tabular}

\subsubsection{Austenite content reduction}

From Fig. 10, the retained austenite is reduced greatly from $8.3 \%$ to $0.5 \%$ in the as deposited condition with $75 \mathrm{kN}$ rolling due to the strain induced shear transformation of austenite to martensite [29]. After aging, the formation of reverted austenite increases the overall austenite content to $3.6 \%$ in the rolled alloy, which is still much lower than the unrolled counterparts 
(13.1\%). The higher austenite content in the rolled alloy than the wrought one may account for the slightly lower $0.2 \% \mathrm{YS}$ and elongation.

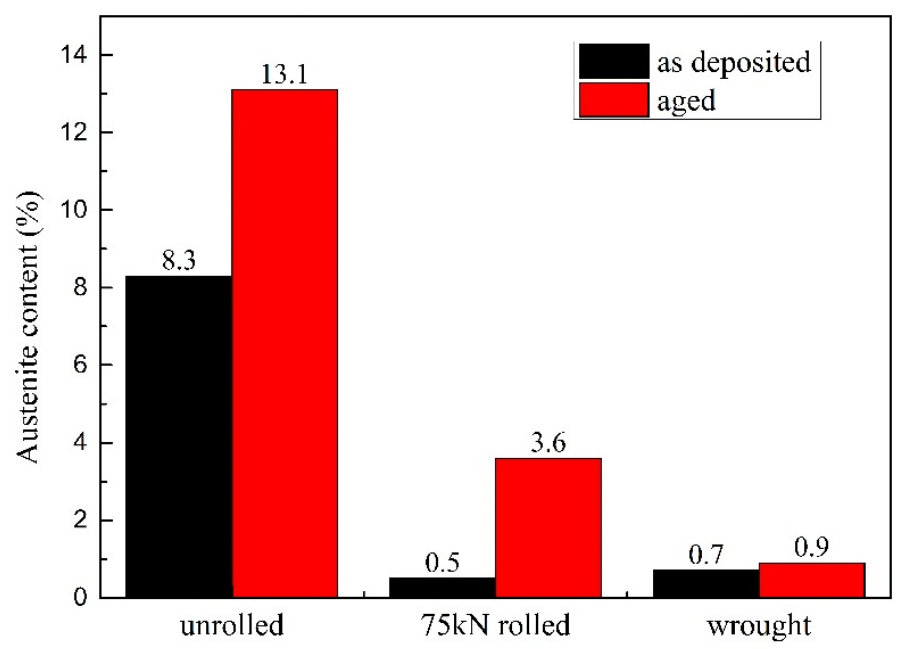

Fig. 10. Volumetric fraction of the austenite measured above the first layer band (data of unrolled and wrought alloy from [6]).

\subsubsection{Work hardening}

Cold working usually leads to a strength increase known as work hardening due to the increased dislocation density. However, in the interpass rolling assisted WAAM process the heat input from successive depositions acts as a non-equilibrium annealing of the strained material and restores the lattice to be of lower dislocation density through recovery and recrystallization [30]; besides, maraging steels possess very low work-hardening rate and can be cold worked with little gains in hardness [2]. Therefore, work hardening in the present study is not expected to contribute greatly to the overall strengthening.

\subsubsection{Strengthening contribution}

Table 4 presents the strength increase in the horizontal direction through different processings benchmarked by the unrolled WAAM maraging steel in the as deposited condition. As can be seen, aging the unrolled alloy results in a strength increase of 292MPa, whilst interpass rolling the WAAM alloy with $50 \mathrm{kN}$ leads to a strength increase of $20 \mathrm{MPa}$ and the strengthening seems 
independent from the rolling load [31] such that with $75 \mathrm{kN}$ rolling the increment is $34 \mathrm{MPa}$. Furthermore, if the WAAM alloy is rolled plus aged, a considerable strength increase of $632 \mathrm{MPa}$ and $633 \mathrm{MPa}$ are observed with the rolling load of $50 \mathrm{kN}$ and $75 \mathrm{kN}$ respectively.

In comparison with the unrolled alloy, the interpass rolled alloy is likely to be strengthened by work hardening, recrystallization and austenite content reduction in the as deposited condition. Considering that the aging temperature $\left(482^{\circ} \mathrm{C}\right)$ is relatively low, the grain structure of the rolled alloy after aging can be assumed to be the same as that in the as deposited condition; actually the possible grain coarsening and austenite reversion during aging will only result in strength loss. Though the UTS improvement from rolling only is not statistically significant, for the overall $632 \mathrm{MPa}(50 \mathrm{kN})$ strengthening with rolling and aging, rolling only, which is the resultant effect of work hardening, recrystallization and austenite content reduction, contributes maximum $20 \mathrm{MPa}(3.2 \%)$ and aging contributes at least $612 \mathrm{MPa}(96.8 \%)$. The pure aging response is enhanced from $292 \mathrm{MPa}$ to $612 \mathrm{MPa}$ (increased by $110 \%$ ) when rolling is applied. The same goes for rolling with $75 \mathrm{kN}$ and rolling contributes $34 \mathrm{MPa}(5.4 \%)$ and aging contributes to $599 \mathrm{MPa}(94.6 \%)$; the aging response is increased by $105 \%$.

Table 4. Strength increase in the horizontal direction through different methods (MPa).

\begin{tabular}{|c|c|c|c|c|}
\hline \multirow[t]{2}{*}{ aging } & \multicolumn{2}{|l|}{ rolling } & \multicolumn{2}{|c|}{ rolling plus aging } \\
\hline & $50 \mathrm{kN}$ & $75 \mathrm{kN}$ & $50 \mathrm{kN}$ & $75 \mathrm{kN}$ \\
\hline 292 & 20 & 34 & 632 & 633 \\
\hline
\end{tabular}

\section{Conclusions}

1. By applying $50 \mathrm{kN}$ interpass cold rolling, the UTS of WAAM maraging steel is improved from $1410 \mathrm{MPa}$ to $1750 \mathrm{MPa}$ which meets the wrought standard (1760MPa). Rolling with higher loads does not show further strength increase. 
2. With rolling applied, the aging response is improved by $110 \%(50 \mathrm{kN})$ and $105 \%(75 \mathrm{kN})$. Among all the active strengthening mechanisms, aging contributes to more than $95 \%$ of the overall strength increase.

3. Rolling results in dendrites reorientation to destroy the previous crystalline order and form new crystallites to weaken the $\{100\}$ texture from 15 times random to 2.57 , which, together with precipitates formation, reduces the anisotropy level from $65 \mathrm{MPa}$ to $15 \mathrm{MPa}$ with $50 \mathrm{kN}$ rolling.

4. Rolling induced energy store triggers recrystallization to form a large number of high-angle grain boundaries, which allows greater atomic mobility and diffusion paths into solution, thus creating a more supersaturated matrix in the solutionizing stage.

5. Rolling induced dislocation multiplication provides more preferred nucleation sites and diffusion paths for the precipitates clustering, thereby enhancing the aging response.

6. With $75 \mathrm{kN}$ rolling, austenite was reduced from $8.3 \%$ to $0.5 \%$ in the as deposited condition; after aging the austenite was higher than wrought alloy (3.6\% vs $0.9 \%)$, but lower than the unrolled alloy (13.1\%).

\section{Acknowledgements}

The authors wish to acknowledge the financial support from China Scholarship Council (NO. 201506680057) and the WAAMMat programme industrial partners. The authors would also like to thank Steve Pope, Dr. Christine Kimpton, and Dr. Tracey Roberts for the assistance during the metallographic and SEM/XRD analysis. The assistance from Flemming Nielsen, Nisar Shah, and Jonathan Pratt during the rolling experiment is much appreciated. The helpful discussion with Jan roman Hönnige on the rolling of Ti and Al alloys is also acknowledged. 


\section{Appendix}

Table 2. Mechanical properties of the WAAM maraging steel.

\begin{tabular}{|c|c|c|c|c|c|c|c|}
\hline & & & & & UTS/MPa & $0.2 \% \mathrm{YS} / \mathrm{MPa}$ & Elongation/\% \\
\hline \multirow[t]{12}{*}{ WAAM } & as deposited & unrolled & & $\mathrm{H}$ & $1118 \pm 94$ & $904 \pm 78$ & $11.7 \pm 0.8$ \\
\hline & & & & $\mathrm{V}$ & $1026 \pm 10$ & $833 \pm 26$ & $8.0 \pm 3.8$ \\
\hline & & rolled & $50 \mathrm{kN}$ & $\mathrm{H}$ & $1138 \pm 118$ & $1014 \pm 102$ & $9.2 \pm 4.5$ \\
\hline & & & & $\mathrm{V}$ & $1013 \pm 8$ & $882 \pm 25$ & $7.1 \pm 0.7$ \\
\hline & & & $75 \mathrm{kN}$ & $\mathrm{H}$ & $1152 \pm 127$ & $993 \pm 101$ & $9.9 \pm 3.7$ \\
\hline & & & & $\mathrm{V}$ & 1030 & 910 & 8.9 \\
\hline & aged & unrolled & & $\mathrm{H}$ & $1410 \pm 32$ & $1303 \pm 29$ & $8.5 \pm 3.3$ \\
\hline & & & & $\mathrm{V}$ & $1345 \pm 19$ & $1227 \pm 31$ & $6.0 \pm 1.7$ \\
\hline & & rolled & $50 \mathrm{kN}$ & $\mathrm{H}$ & $1750 \pm 17$ & $1654 \pm 37$ & $4.3 \pm 1.0$ \\
\hline & & & & $\mathrm{V}$ & $1735 \pm 10$ & $1623 \pm 18$ & $4.8 \pm 0.3$ \\
\hline & & & $75 \mathrm{kN}$ & $\mathrm{H}$ & $1751 \pm 3.4$ & $1634 \pm 41$ & $6.1 \pm 1.8$ \\
\hline & & & & $\mathrm{V}$ & - & - & - \\
\hline \multirow[t]{2}{*}{ wrought } & Solution [2] & & & & $1000-1140$ & $725-895$ & $8-16$ \\
\hline & aged [32] & & & & 1760 & 1720 & 10 \\
\hline
\end{tabular}

\section{References}

[1] S.L. Campanelli, A. Angelastro, C.G. Signorile, G. Casalino, Investigation on direct laser powder deposition of $18 \mathrm{Ni}$ (300) marage steel using mathematical model and experimental characterisation, Int. J. Adv. Manuf. Technol. 89 (2017) 885-895. doi:10.1007/s00170-016-9135-x.

[2] ASM International, ASM Handbook: Volume 1 Properties and selection: irons steels and high performance alloys, 10th ed., ASM International, Materials Park, Ohio, 2001. doi:10.1016/S0026-0576(03)90166-8.

[3] B. Cong, J. Ding, S. Williams, Effect of arc mode in cold metal transfer process on porosity of additively manufactured Al-6.3\% Cu alloy, Int. J. Adv. Manuf. Technol. 76 (2014) 1593-1606. doi:10.1007/s00170-014-6346-x.

[4] S.W. Williams, F. Martina, A.C. Addison, J. Ding, G. Pardal, P. Colegrove, Wire+Arc Additive Manufacturing, Mater. Sci. Technol. $00 \quad$ (2015) 1-7. doi:10.1179/1743284715Y.0000000073. 
[5] K. Huang, R.E. Logé, A review of dynamic recrystallization phenomena in metallic materials, Mater. Des. 111 (2016) 548-574. doi:10.1016/j.matdes.2016.09.012.

[6] X. Xu, S. Ganguly, J. Ding, S. Guo, S. Williams, F. Martina, Microstructural evolution and mechanical properties of maraging steel produced by wire+arc additive manufacture process, Mater. Charact. (2018). doi:10.1016/j.matchar.2017.12.002.

[7] J. Donoghue, A.A. Antonysamy, F. Martina, P.A. Colegrove, S.W. Williams, P.B. Prangnell, The effectiveness of combining rolling deformation with Wire-Arc Additive Manufacture on $\beta$-grain refinement and texture modification in Ti-6Al-4V, Mater. Charact. 114 (2016) 103-114. doi:10.1016/j.matchar.2016.02.001.

[8] F. Martina, P.A. Colegrove, S.W. Williams, J. Meyer, Microstructure of Interpass Rolled Wire + Arc Additive Manufacturing Ti-6Al-4V Components, Metall. Mater. Trans. A Phys. Metall. Mater. Sci. 46 (2015) 6103-6118. doi:10.1007/s11661-0153172-1.

[9] E.A. Jägle, P.-P. Choi, J. Van Humbeeck, D. Raabe, Precipitation and austenite reversion behavior of a maraging steel produced by selective laser melting, J. Mater. Res. 29 (2014) 2072-2079. doi:10.1557/jmr.2014.204.

[10] K. Kempen, E. Yasa, L. Thijs, J.P. Kruth, J. Van Humbeeck, Microstructure and mechanical properties of selective laser melted 18Ni-300 steel, Phys. Procedia. 12 (2011) 255-263. doi:10.1016/j.phpro.2011.03.033.

[11] S.L. Campanelli, N. Contuzzi, A.D. Ludovico, Manufacturing of 18 Ni Marage 300 Steel Samples by Selective Laser Melting, Adv. Mater. Res. 83-86 (2009) 850-857. doi:10.4028/www.scientific.net/AMR.83-86.850.

[12] E. Yasa, K. Kempen, J. Kruth, Microstructure and mechanical properties of Maraging Steel 300 after selective laser melting, in: Proc. 21 st Int. Solid Free. Fabr. Symp., 2010: pp.

383-396.

http://utwired.engr.utexas.edu/lff/symposium/proceedingsArchive/pubs/Manuscripts/2 010/2010-32-Yasa.pdf.

[13] G. Casalino, S.L. Campanelli, N. Contuzzi, A.D. Ludovico, Experimental investigation and statistical optimisation of the selective laser melting process of a maraging steel, Opt. Laser Technol. 65 (2015) 151-158. doi:10.1016/j.optlastec.2014.07.021.

[14] C. Tan, K. Zhou, W. Ma, P. Zhang, M. Liu, T. Kuang, Microstructural evolution, nanoprecipitation behavior and mechanical properties of selective laser melted highperformance grade 300 maraging steel, Mater. Des. 134 (2017) 23-34. doi:10.1016/j.matdes.2017.08.026.

[15] E.A. Jägle, P. Choi, J. Van Humbeeck, D. Raabe, Precipitation and austenite reversion behavior of a maraging steel produced by selective laser melting, J. Mater. Res. 29 (2014) 2072. doi:10.1557/jmr.2014.204.

[16] X. Xu, J. Ding, S. Ganguly, C. Diao, S. Williams, Oxide accumulation effects on wire+arc layer-by-layer additive manufacture process, J. Mater. Process. Tech. 252 (2018) 739-750. doi:10.1016/j.jmatprotec.2017.10.030.

[17] Y. Lian, J. Huan, J. Zhang, C. Zhao, W. Gao, Z. Zhang, M. Ma, Effects of cold rolling on the microstructure and properties of Fe-Cr-Ni-Mo- Ti maraging steel, Mater. Sci. Eng. A. 712 (2018) 663-670. doi:10.1016/j.msea.2017.12.041. 
[18] J. Gu, J. Ding, S.W. Williams, H. Gu, P. Ma, Y. Zhai, The effect of inter-layer cold working and post-deposition heat treatment on porosity in additively manufactured aluminum alloys, J. Mater. Process. Technol. 230 (2016) 26-34. doi:10.1016/j.jmatprotec.2015.11.006.

[19] J. Gu, J. Ding, S.W. Williams, H. Gu, J. Bai, Y. Zhai, P. Ma, The strengthening effect of inter-layer cold working and post-deposition heat treatment on the additively manufactured Al- 6.3Cu alloy, Mater. Sci. Eng. A. 651 (2016) 18-26. doi:10.1016/j.jmatprotec.2015.11.006.

[20] P. a. Colegrove, H.E. Coules, J. Fairman, F. Martina, T. Kashoob, H. Mamash, L.D. Cozzolino, Microstructure and residual stress improvement in wire and arc additively manufactured parts through high-pressure rolling, J. Mater. Process. Technol. 213 (2013) 1782-1791. doi:10.1016/j.jmatprotec.2013.04.012.

[21] J. Ding, P. Colegrove, F. Martina, S. Williams, R. Wiktorowicz, M.R. Palt, Development of a laminar flow local shielding device for wire+arc additive manufacture, J. Mater. Process. Technol. 226 (2015) 99-105. doi:10.1016/j.jmatprotec.2015.07.005.

[22] J. Honnige, C. Paul, B. Ahmad, M.E. Fitzpatrick, S.Ganguly, T.L. Lee, S.W. Williams, Residual stress and texture control in Ti-6Al-4V wire + arc additively manufactured intersections by stress relief and rolling, Mater. Des. 150 (2018) 193-205. doi:10.1016/j.matdes.2018.03.065.

[23] F.H. Lang, N. Kenyon, Welding of Maraging Steels, Weld. Res. Concil. (1971) 41.

[24] P. Baldi, A.D. Long, A Bayesian framework for the analysis of microarray expression data: regularized $t$-test and statistical inferences of gene changes, Bioinformatics. 17 (2001) 509-519. doi:10.1093/bioinformatics/17.6.509.

[25] ASTM, ASTM E112-13: Standard test methods for determining average grain size, ASTM Int. (2013) 1-28. doi:10.1520/E0112-13.1.4.

[26] Y. Estrin, H.S. Kim, F.R.N. Nabarro, A comment on the role of Frank-Read sources in plasticity of nanomaterials, Acta Mater. 55 (2007) 6401-6407. doi:10.1016/j.actamat.2007.07.052.

[27] T. Gladman, Precipitation hardening in metals, Mater. Sci. Technol. 15 (1999) 30-36. doi:10.1179/026708399773002782.

[28] A. International, ASM Handbook: Volume 4 Heat Treating, in: ASM Handb., ASM International, 1991: p. 2173. doi:10.1016/S0026-0576(03)90166-8.

[29] P. Haušild, V. Davydov, J. Drahokoupil, M. Landa, P. Pilvin, Characterization of straininduced martensitic transformation in a metastable austenitic stainless steel, Mater. Des. 31 (2010) 1821-1827. doi:10.1016/j.matdes.2009.11.008.

[30] J.W. Morris, Dislocation Plasticity: Overview, Introd. to Mater. Sci. i (2007) 1-36. http://www.mse.berkeley.edu/groups/morris/MSE205/Extras/dislocation plasticity.pdf.

[31] Z. Yang, J. Su, J. Chen, Effect of Prior Cold Rolling Deformation on Strengthening of Maraging Steel, Iron Steel. 43 (2008) 66-69.

[32] ASTM, Standard Specification for Superstrength Alloy Steel Forgings 1, Astm. (2015) 1-7. doi:10.1520/A0579. 
2018-12-28

\title{
Improving mechanical properties of wire
} + arc additively manufactured maraging steel through plastic deformation enhanced aging response

\author{
Xu, Xiangfang
}

Elsevier

Xu X, Ganguly S, Ding J, et al., Improving mechanical properties of wire + arc additively manufactured maraging steel through plastic deformation enhanced aging response. Materials Science and Engineering A: Structural Materials, Volume 747, February 2019, pp. 111-118 https://doi.org/10.1016/j.msea.2018.12.114 Downloaded from Cranfield Library Services E-Repository 